\title{
Realidad y ficción en el episodio galdosiano Memorias de un cortesano de /8/5
}

\author{
Reality and Fiction in the Galdosian Episode: \\ Memorias de un cortesano de 1815 \\ (Memories of a courtier of /8/5)
}

\author{
Antonio ManUEL Moral Roncal \\ Universidad de Alcalá \\ Facultad de Filosofía y Letras \\ Departamento Historia y Filosofía \\ cl. Colegios, 2 \\ 2880 I Alcalá de Henares (Madrid) (España) \\ antonio.moral@uah.es
}

iD

RECIBIDO: FEBRERO DE 2021

ACEPTADO: MARZO DE 202

Resumen: En este artículo se analiza la imagen que Galdós construyó de la sociedad cortesana, en la Restauración fernandina de 1814, a través de su Episodio Nacional Memorias de un cortesano de 18/5, basándose especialmente en obras de historiografía liberal del siglo XIX y en su propia experiencia vital. Con el apoyo de modernos y renovadores estudios sobre la Real Casa y Patrimonio, se analizan las semejanzas y diferencias entre las visiones actuales y aquellas que conformó Galdós sobre una institución clave todavía en la vida política y social de la España del siglo XIX.

Palabras clave: Sociedad cortesana. Reinado de Fernando VII. Camarilla. Besamanos. Memorias de un cortesano de $18 / 5$.

Abstract: This article analyzes the image that Galdós built of court society, in the Fernandina Restoration of 1814, through his National Episode Memories of a courtesan of 18/5, based especially on works of liberal historiography of the 19th century and on his own life experience. With the support of modern and renovating studies on the Royal House and Heritage, the similarities and differences between current views and those that Galdós formed about a key institution still in the political and social life of 19 th century Spain are analyzed.

Keywords: Courtesan society. Reign of Fernando VII. Camarilla. Kissing hands Ceremony. Memories of a courtier of $18 / 5$ 
ANTONIO MANUEL MORAL RONCAL

\section{LA INFLUENCIA DEL MOMENTO HISTÓRICO}

Para Antonio Dorca, el fracaso del Sexenio Revolucionario (I868-I874), que tantas esperanzas de renovación y progreso había generado en la opinión pública liberal en sus comienzos, provocó un hondo desencanto en Benito Pérez Galdós, lo cual repercutió, lógicamente, en su labor literaria'. En 1874 el régimen republicano se encontraba en perenne crisis entre el intento cesarista del general Serrano, la dictadura militar, las guerras carlista, cubana y cantonal. Las luchas por el poder entre los partidos de la coalición revolucionaria, junto a la ácida crítica de la prensa contra todo y contra todos, habían provocado una clara inestabilidad, que se tradujo en un baile continuo de gobiernos y regímenes políticos. Quienes habían criticado el reinado isabelino habían caído en todo aquello que denunciaban. La segunda serie de los Episodios Nacionales - donde se inserta el volumen de este estudio-, literariamente superior a la primera, emitió una sensación de descomposición y fatalismo desde sus primeras líneas ${ }^{2}$. Galdós vaticinó serias desgracias en una España que se encontraba entonces desnortada, sin fe, en el abismo de las guerras civiles. En el episodio El equipaje del rey José, el espanto de la guerra de la Independencia adquirió unas simetrías decisivas con ese año fatídico para España. El ejército, que había provocado la llegada del Sexenio con la revolución septembrina, lo cerró, siempre dentro del abanico de opciones liberales, con su apoyo al proyecto restaurador de Cánovas del Castillo.

El siguiente episodio, Memorias de un cortesano de 1815 , fue publicado en el año de la llegada de Alfonso XII a España como nuevo monarca, personificación del régimen canovista que empezaba a construir sus cimientos. Cabe preguntarse, como Robert W. Dash, si, a través de sus páginas, Galdós intentó advertir a los vencedores políticos del momento de una posible repetición de los errores de la primera Restauración, la de Fernando VII, tras el fin de su exilio francés ${ }^{3}$. Aunque sería más correcto hablar, en todo caso, de una advertencia para no redundar en los errores políticos que provocaron el derrocamiento de la madre del rey, Isabel II. Cánovas había logrado unir a los liberales conservadores y unionistas

\footnotetext{
I Dorca, 2017, p. 273.

${ }^{2}$ La primera serie se abrió con la publicación de Trafalgar en 1873. La crítica ha entroncado el Episodio Nacional dentro de la novela histórica, aunque el adjetivo nacional remite a otra exigencia diferente a la narración de hechos cercanos ya que presupone que incluye una reflexión sobre el estado general de toda España. Además, el escritor no debe trastocar hechos, fechas, lugares y personajes para cuya exactitud debe recurrir al trabajo de los historiadores. Es ahí donde existe un claro puente entre Literatura e Historia que debe ser respetado, aunque no todos los escritores lo han hecho como señala González Martín, 1994, pp. 73-92.

3 Dash, 2000, p. 280. Asimismo, Baquero Goyanes, 1970-197I, Pp. 143-160; Navascués, 1987, pp. 49I-5I0; Whiston, I99I, Pp. I-13.
} 


\section{REALIDAD Y FICCIÓN EN EL EPISODIO GALDOSIANO}

en torno suyo, lo que facilitaría la formación de su Partido Conservador, pero aun existían antiguos políticos moderados que no habían aprendido nada de la experiencia del Sexenio Revolucionario y que creían que todavía podían resucitar el viejo partido isabelino, al cual se le responsabilizaba de haber intentado monopolizar la Monarquía constitucional. Cánovas había logrado que Isabel II asumiera que su vuelta a España no se produciría inmediatamente, al igual que ni la de su marido ni la de su hermana ni su cuñado, el duque de Montpensier. Representantes de una corte que deseaba dejar en el recuerdo histórico, el líder conservador aceptó que solo la infanta Isabel, hermana de Alfonso XII, le acompañara inicialmente en Madrid, la cual se encargaría de organizar una nueva estructura cortesana junto al duque de Sexto, fiel canovista, que fue nombrado mayordomo mayor de la Real Casa y Patrimonio 4 .

Galdós - como otros escritores liberales- ayudó a cimentar la interpretación que definía el movimiento de la historia como un progreso continuo hacia el paraíso terrestre llamado modernidad. Aquellos elementos que, aparentemente, se oponían a ese desarrollo histórico fueron descritos y satirizados por la literatura afín como elementos que retardaban o dificultaban un proceso de modernización indiscutible. $Y$ si ese proceso fallaba no era culpa ni de la clase política ni de la práctica de esas ideologías modernizadoras, sino de una serie de obstáculos; entre ellos, la Iglesia católica y la corte fueron los preferidos por la crítica progresista. La sociedad cortesana fue presentada como un ámbito de poder paralelo al oficial que creaba y deshacía gobiernos, retrasaba la consolidación de políticas secularizadoras y democráticas. Sin embargo, la historiografía contemporánea ha desvelado los constantes intentos de controlar la corte por parte de esa clase política liberal, la cual intentó introducir sus propias redes de poder en la misma. Intentó, pues, aprovechar esa institución en su propio beneficio 5 .

Memorias de un cortesano de 1815 , lejos de ser un resumen de toda una fase histórica, mostró a los lectores la realidad desde un punto de vista parcial e

\footnotetext{
${ }^{4}$ Sobre la corte en el reinado de Alfonso XII no existe una monografía, pero una aproximación notable es el capítulo sobre la misma en López Sánchez, 2018; El análisis de la Real Casa y Patrimonio en el siglo XIX ha tenido, en los últimos años, un claro avance, fruto de grupos de investigación de la Universidad Complutense, Rey Juan Carlos y Alcalá, como demuestra el conjunto de trabajos de Sánchez, 2018; San Narciso y Sánchez, 2018; y Sánchez, 2019. Centrado en el reinado del protagonista de las Memorias de un cortesano de 1815 es el trabajo de Moral Roncal, 2005. Un clásico de referencia es Mozzarelli y Olmi, 1983.

${ }^{5}$ El caso más claro se produjo en el Sexenio Revoluciónario (1868-1874) que vive Galdós. La coalición revolucionaria que había derribado el trono de Isabel II bajo la acusación de corrupción y monopolio del poder político en la corte, intentó controlar la Casa de Amadeo I desde sus inicios al final. Conocida es la maniobra de Serrano que, a cambio de aceptar ser padrino del último hijo del rey, exigió la presidencia del gobierno, el decreto de disolución de Cortes y el nombramiento de mayordomo mayor para uno de sus familiares. De esa manera controlaría la corte, ya que mayordomía mayor estaba a cargo de un peón del Partido Progresista y, más concretamente, de Olózaga en 1873. La especialista en el estudio de esta corte es Pascual Sastre, 2018, Pp. 263-299; 2020, pp. 347-380.
} 


\section{ANTONIO MANUEL MORAL RONCAL}

ideológicamente definido, pues no en vano Galdós narró, a través de la obra completa de los Episodios Nacionales, la visión literaria que el liberalismo tuvo del siglo XIX español. La creación del personaje principal de este Episodio, Juan Bragas de Pipaón, constituyó un punto decisivo en la evolución literaria del escritor canario. Si bien, para algunos críticos fue un logro esencialmente técnico, otros investigadores observaron al protagonista como un ejemplo inicial de la progresiva preocupación de su creador por plasmar la vida interior de sus personajes. Así, Jacques Beyrie emplazó la invención de Pipaón dentro del progreso anímico del narrador ${ }^{6}$. Y si cada interlocutor de la novela realista personificó una perspectiva personal sobre la estructura social impresionada en el texto, como se estima desde las primeras novelas de estas memorias, la exageración paródica del estilo de Pipaón ayudó a presentar la Restauración fernandina de 1814 como un proyecto de ambición personal, enmascarado de defensa de la tradición, del catolicismo y de la legitimidad dinástica. De esta manera, Galdós estableció una irónica relación entre los lectores y su protagonista que facilitó la entrada inmediata, y a la vez invectiva, a la naturaleza interior de los partidarios del absolutismo.

Para Ramón Espejo, Pipaón - que se convertirá, a lo largo del texto, de funcionario oscuro en cortesano y alto funcionario- fue un ejemplo de narrador poco honesto, aunque si bien irónico, lo que facilitó la comunicación clara con el lector de entonces. Su papel en la obra no se redujo a ser un mero espejo de la corrupción y oportunismo de muchos absolutistas, que intentaron aprovechar el cambio político, sino que también se acercó al autoengaño vital y a la analogía entre la manipulación discursiva de la realidad y el discernimiento particular ${ }^{7}$. Para Whiston, Pipaón resulta ser más caricatura que personaje, al intentar falsear hasta la inverosimilitud los hechos de aquellos tiempos, distorsionando la historia de España con un código de valores inverso.

En diciembre de 1874 el ejército español no se autoengañó, no actuó como en I8|4: se negó a apoyar la opción más tradicionalista —el carlismo- o aquella que para la opinión pública liberal recordaba más el absolutismo. Su apuesta por la Monarquía de Sagunto no fue comparable a su apoyo inicial a la Monarquía fernandina en 1814 - por otra parte al igual que hicieron las fuerzas británicas comandadas por el duque de Wellington ${ }^{2}$ - pero tal vez Galdós decidió mostrar su miedo, su temor, su desconfianza ante el cambio político que observaba, por

\footnotetext{
${ }^{6}$ Beyrie, 1987, pp. 213-232.

${ }^{7}$ Espejo-Saavedra, 2003, pp. 89-105.

${ }^{8}$ Whiston, 1991, p. 6; lo cual contrasta con Seco Serrano 1970-7I, Lida, I968 y Canal, 2013.

${ }^{9}$ Sobre el papel de las fuerzas británicas ver La Parra, 2014, pp. 205-222; y el carácter de esta restauración es analizado, dentro de un abanico de alternativas políticas, por Butrón Prida 2014, pp. 59-78.
} 


\section{REALIDAD Y FICCIÓN EN EL EPISODIO GALDOSIANO}

lo que resolvió utilizar la sátira, la ironía y la caricatura en Memorias de un cortesano de 1815 , siendo recursos más que conocidos y habituales para la crítica socio-política. En opinión de Dash, el escritor realista llevó estas técnicas a extremos que semejaron prever la teoría del esperpento valleinclanesco ${ }^{10}$.

\section{CÓMO LLEGAR A SER CORTESANO}

Juan Bragas de Pipaón, personaje secundario en el Episodio inmediatamente anterior - El equipaje del rey José- se inventa a sí mismo, en la mejor tradición cervantina, al dotarse de una identidad propia. Adopta el nombre de su lugar de origen, la villa riojana-alavesa de Pipaón, como Guzmán de Alfarache, el Lazarillo de Tormes y otros pícaros, ocultando y abandonando el despectivo y desagradable apellido de Bragas. Si para Dash es un primer ejemplo de la tendencia de Galdós hacia la narrativa esperpéntica ", en nuestra opinión resulta también esclarecedora de la mentalidad y la cultura nobiliaria de la época, ya que resultaba necesario, para lograr un alto puesto en administración y en la corte, desplegar cierta aura de nobleza, de título — viejo o reciente-, de hidalguía y ayudaba para ello lucir un apellido que sonara a cierto lustre. Pipaón actúa según esa mentalidad nobiliaria, que logró una amplia supervivencia y adaptación a las mutaciones políticas del siglo XIX, como la historiografía más reciente ha analizado ${ }^{12}$. Si las principales jefaturas de la Real Casa —mayordomo mayor, sumiller, caballerizo mayor, camarera mayor - estaban reservadas para los grandes de España; si las categorías de gentilhombre o dama de la reina se abrían no solo a grandes sino también a la nobleza titulada o a quienes habían realizado grandes servicios a la Corona, había clases de criados de Su Majestad - como los mayordomos de semana- a las cuales podían aspirar miembros de los Consejos y de la alta administración militar y civil; es decir, que podían abrirse a hidalgos y nobleza corporativa. Precisamente, Pipaón aspiraba a un puesto en el Real Consejo y Cámara de Castilla, para calentar su sillón ${ }^{13}$, término ambiguo que Galdós utilizó para dar

\footnotetext{
${ }^{10}$ Dash, 2000, p. 280; lo cual contrasta con la visión de Álvarez Junco, 2017.

II Dash, 2000, p. 282.

12 Desde el clásico estudio de Powis, 2007, hasta el conjunto de aportaciones del Grupo de Estudios sobre la Nobleza, 2019. La adaptación de la nobleza a los cambios económicos del siglo XIX y a la revolución liberal ha sido analizada, desde múltiples perspectivas, en análisis como Carmona Vidal, 200I; Hernández Montalbán, 1999; Rueda Hernanz, 2015, pp. 4I-58; sin olvidar la obra fundamental de Sánchez Marroyo, 2014 y su resumen en 2015, pp. 5-39. La historiografía extranjera ha apuntado caminos sugerentes de adaptación y relación con nuevas élites en los trabajos de Higgs, 1993, pp. 87-100; Mosse, 2000, pp. 133-168; Tudesq, 1988, pp. 121-135; Wasson, 2006. Adaptación que también tuvo que sufrir la nobleza en el ámbito político como advierten Cuenca Toribio y Miranda García, 1998, pp. 159-168; Daumard, 1988, pp. 8I-I04; Moral Roncal, 2015, pp. 8I-II3; Risco, 2010, pp. 187-206.

13 Pérez Galdós, 1884a, p. 189.
} 


\section{ANTONIO MANUEL MORAL RONCAL}

a entender al lector que no se debía tener muy en serio al protagonista, que aspiraba a lograr un honor sin méritos y sin necesidad de realizar esfuerzo destacado ni trabajo digno alguno. En esa estrategia por semejar mayor brillo hidalgo, el protagonista confiesa al lector que comenzó a aprender a vestir con elegancia, ante el asombro de quienes le habían conocido anteriormente, y a visitar casas de viudas y huérfanas relacionadas con títulos de Castilla ${ }^{14}$. La falsa apariencia persiste siempre unida a uno de sus elementos permanentes y no el menor: la vanidad $^{15}$. De ahí que el lector la aprecie continuamente en las memorias de Pipaón, pues es un carácter del cual el protagonista no puede sustraerse ni cuando narra sus avatares amorosos ni sus intentos de ascensión cortesana.

Tradicionalmente, en la literatura clásica junto al pícaro se encontraba el amo y, en el caso de Juan de Pipaón, resulta ser un gran personaje que el protagonista no cita por su verdadero nombre, despertando así el interés del lector, escondiendo su identidad con hipérboles irónicas y frases populares - «nobilísimo, con aquel sin par sujeto... personajes insignes no deben ser puestos a la vergüenza de las letras de molde, donde corren riesgo de que la Historia y la Posteridad... le tomen por su cuenta, atribuyéndoles esta o la otra picardía y desfigurando con pérfido criterio sus honrados manejos. Pero sin nombrar al santo, puedo referir los milagros» ${ }^{16}$ - Decide llamarlo "Don Buenaventura» -en alusión a su buena suerte al conocerlo- pero el historiador localiza rápidamente al personaje al señalar que había acaudillado a los diputados realistas de las Cortes gaditanas y redactado el «Manifiesto de los persas» ${ }^{17}$ : bajo ese pseudónimo se ocultaba el marqués de Mataflorida, Bernardo Mozo de Rosales. Galdós criticó ácidamente al personaje, al que acusa de inventarse pruebas falsas — con la ayuda inestimable de la caligrafía de Pipaón- que respalden la represión de los liberales y partidarios de la constitución de 1812 , imputándoles una conspiración para derribar la Monarquía y proclamar una «república iberiana» ${ }^{18}$. Sin embargo, por la torpeza de un cura granadino y de un criado de la duquesa de Osuna, se descubre la maniobra y todo se desbarata. Resulta lógico que Galdós aludiera a esa aristócrata ya que fue un conocido ejemplo de mecenas ilustrada

\footnotetext{
${ }^{14}$ Pérez Galdós, 1884a, p. 218.

15 Una vez que Pipaón se introduce en los círculos palatinos, empezará a creer que él es el único cortesano que sabe manejar los hilos que controlan las acciones de los demás. Sobre la importancia de aparentar y ser considerado noble, en la historia de España, resulta imprescindible la consulta de Barrios y Alvarado, 2019.

16 Pérez Galdós, 1884a, p. 191.

${ }^{17}$ El manifiesto de los persas resumió la oposición del grupo realista al liberalismo de las Cortes de Cádiz, así como principios de afirmación de la monarquía católica y representativa, como se analiza en Ayuso, 2015, Pp. 5-33 y La Parra, 2018, pp. 224-228.

18 Pérez Galdós, 1884a, p. 192.
} 
que tuvo que adaptarse pragmáticamente durante el reinado de Fernando VII a los nuevos tiempos.

En la narración, Pipaón, sin embargo, continúa colaborando con la represión absolutista, contratando manolos y chisperos de los bajos fondos madrileños para amedrentar y denunciar a liberales. Por todo lo cual, su protector le coloca como oficial segundo de Paja y Utensilios, en Hacienda, desde donde se encarga de perder expedientes de aquellos que le pagan por ello, en dinero o en especie, de tal manera que la visión de la administración resulta patética y desastrosa, la amoralidad más absoluta reina entre el funcionariado. Como ejemplo de la inversión de valores en la justicia del Estado absolutista, en los primeros momentos de su restablecimiento, el protagonista escribe que «todo no había de ser blandura, porque en aquellos días restablecimos la Inquisición». El elemento picaresco que destacan los historiadores de la Literatura va en aumento cuando Pipaón se encuentra sirviendo a un nuevo amo sin contar cómo va abandonando lentamente a don Buenaventura. Se trata de otro personaje histórico, don Blas Ostolaza, a quien conoce en la tertulia de las señoras de Porreño, una de las cuales es hermana del marqués del mismo nombre, siendo las otras dos mujeres hija $y$ sobrina del noble'19. Galdós se recrea en hundir al personaje ante el lector al comparar su cargo como confesor del infante don Carlos y predicador de palacio con la revelación de los pensamientos de sus compañeros en las Cortes de Cádiz, donde fue diputado. Un confesor que no es discreto, que descubre opiniones de personas que les puede costar la vida, la cárcel o el exilio no solo resulta algo paradójico sino impropio de un sacerdote católico. Su ser corrupto se desvela al solicitar a Pipaón que realice uno de sus deslices administrativos a favor de un hermano suyo. Al mismo tiempo, le ridiculiza al mostrarlo contento por el restablecimiento de la Inquisición y, sobre todo, al explicar que su influencia sobre el infante don Carlos era tan grande que urociaba el lecho de Su Alteza con agua bendita para alejar los sueños pecaminosos» ${ }^{20}$.

Ostolaza es quien introduce en palacio a Pipaón, concretamente en la tertulia del infante don Antonio, simbolizando - a nuestro entender- el papel del clero como consejero de la Corona, como estamento victorioso con la Restauración fernandina, a salvo de las reformas liberales propuestas en las Cortes de Cádiz. Y es que este evidente anticlericalismo que muestra Galdós formó parte decisiva de las culturas políticas del liberalismo español, traspasándose de forma clara a las primeras décadas del siglo XX. Ser liberal implicaba, en menor o mayor

\footnotetext{
${ }^{19}$ Dash comete el error de señalar que Pipaón conoce al sacerdote en la tertulia del infante don Antonio. No es así, ya que será Blas de Ostolaza quien le introduzca en los círculos palatinos. Dash, 2000, p. 282; Pérez Galdós, 1884a, pp. 218-219.

20 Pérez Galdós, 1884a, p. 221.
} 
grado, un anticlericalismo revolucionario, que rompía con esa crítica creyente y devota contra el clero de los tiempos medievales y modernos ${ }^{21}$.

Sin embargo, todavía falta una biografía que, lejos del presentismo político, aclare la trayectoria de este ferviente realista, que no parece fuera tan burdo como el personaje galdosiano. Nacido en Trujillo del Perú, Blas de Ostolaza recibió una beca supernumeraria para ser admitido en el seminario de San Carlos y San Marcelo de su ciudad natal. Lo sobresaliente de sus estudios le hizo ganarse el aprecio del obispo Martínez de Compañón, cursando cánones y leyes en Lima. Allí se hizo cargo de la cátedra de derecho civil, siendo doctor en teología y abogado de la Real Audiencia, hasta alcanzar la dirección del seminario limeño. Continuó su carrera en España donde alcanzó el cargo de teniente cura, dos capellanías de honor y el privilegio de oficiar misas a la familia real en 1806. Para desempeñar mejor estas responsabilidades palatinas, se doctoró en cánones en la universidad de Osma. Dos años más tarde, acompañó a Fernando VII a Bayona como miembro de su séquito y permaneció a su lado en su cautiverio en Valençay hasta comienzos de 1809, cuando las autoridades napoleónicas ordenaron la vuelta a España de la mayor parte de los servidores españoles. Ostoloza llevaba escondido un poder otorgado por el rey para que defendiese sus derechos al trono tanto en España como en las Américas, a donde quiso trasladarse logrando tan solo arribar a Cádiz, convirtiéndose en diputado realista en las Cortes. Firmante del «Manifiesto de los persas», Ostolaza recibió la dignidad de deán de la catedral de Murcia. Y, contrastando con su papel en Memorias de un cortesano, el tercer domingo de adviento de 1814 se escuchó su palabra severa criticando la camarilla palaciega que rodeaba al rey alejándolo del recto gobierno. Este sermón inició su lenta caída en desgracia, pues dos años más tarde fue desterrado a Murcia donde soportó una falsa acusación de extralimitación en la dirección espiritual de la casa de huérfanas. Para Fernán Altuve y Francisco Candel, detrás se encontraba una maniobra del ministro Juan Esteban Lozano de Torres ${ }^{22}$.

Don Antonio de Borbón, hijo de Carlos III, había llevado una vida tranquila y protocolaria durante los reinados de su padre y su hermano, como infante segundón. Galdós le describe según las visiones de su época, como una persona poco interesada en su propia educación que, sin embargo, «aprendió a conspirar en su vejez» ${ }^{23}$, alusión a su participación en el cortesano partido fernandino de comienzos del siglo XIX, partidario de derrocar del poder a Manuel Godoy y de encumbrar en el trono a Fernando VII. Su fidelidad a su sobrino continuó durante

\footnotetext{
${ }^{21}$ Sobre la evolución del anticlericalismo, desde tiempos medievales hasta la edad contemporánea, puede consultarse Moral Roncal, 2014, pp. 229-239.

${ }^{22}$ Candel, 198I; Altuve-Febres, 2007, pp. 14I-163.

${ }^{23}$ Pérez Galdós, 1884a, p. 223.
} 


\section{REALIDAD Y FICCIÓN EN EL EPISODIO GALDOSIANO}

la guerra de la Independencia, al decidir acompañarle a su exilio en Valençay, en vez de marchar con su hermano Carlos IV a Marsella y Roma. Por eso, solo don Carlos María Isidro y don Antonio formaron parte de la comitiva familiar que acompañó al rey en su triunfal regreso a España en I8I4. Exagerando bastante, Galdós apunta que de la tertulia que organizó don Antonio en el palacio real de Madrid - formada por el nuncio, el duque del Infantado ${ }^{24}$, los canónigos Escóiquiz y Ostolaza- emergieron las decisiones que favorecen el restablecimiento de la Inquisición y otros decretos de carácter absolutista. Allí Pipaón continúa haciendo los favores que le solicitan esos personajes en sus oficinas, hasta que finalmente:

Crecía mi favor como la espuma y a los comienzos de 1815 pude pasar del cuarto del príncipe al del Rey, que era el Olimpo de la cortesanía, y trabar comercio más íntimo con personajes del mayor prestigio y que, al decir de las gentes, traían en los cinco dedos de su mano toda la grandeza del reino, del cual eran árbitros, sin dar de ello cuenta a Dios ni al Diablo25.

\section{LAS CAMARILLAS}

Para escribir sobre la primera Restauración, Galdós consultó la obra de José Presas, Pintura de los males que ha causado a la España el gobierno absoluto de los dos últimos reinados y de la necesidad del restablecimiento de las antiguas Cortes o de una carta constitucional dada por el rey Fernando, impresa en I827; el conocido volumen de Estanislao de Koska Vayo, Historia de la vida y reinado de Fernando VII de España, publicada en 1842 y la Historia General de España de Modesto Lafuente, editada entre 1850 y 1867 en varios volúmenes ${ }^{26}$. Por ello, los caracteres de los miembros de la camarilla regia y su propia materialidad nacen de esas lecturas y se trasladan a la narración.

Pero sacóme de mis meditaciones el duque mismo llevándome de sala en sala, hasta una en que acostumbraban a reunirse los cortesanos para arreglar sus cuentas de favoritismo unos con otros, sopesar su respectiva influencia y regodearse en común de ver la buena marcha de los asuntos del gobierno ${ }^{27}$.

\footnotetext{
${ }^{24}$ Personaje de gran importancia histórica en esa época pero que, curiosamente, Galdós no le presta apenas atención en este episodio. Sobre su figura existen varios acercamientos, Carrasco, 2006, pp. 305-336; Alarcón Alarcón, 2012, pp. 165-186.

${ }^{25}$ Pérez Galdós, 1884a, p. 231.

${ }^{26}$ Valera, 1943, p. 17; Hinterhäuser, 1963, p. 59; Dorca, 2017, pp 262-264.

27 Pérez Galdós, I884a, p. 292.
} 


\section{ANTONIO MANUEL MORAL RONCAL}

Sin embargo, quien introduce a Pipaón en la camarilla regia es Antonio Ugarte, personaje histórico que, para Galdós, simboliza perfectamente al pequeño grupo de consejeros de Fernando VII que formaban y derribaban gobiernos a su arbitrio. Lo describe como un antiguo maestro de baile con muchísimas habilidades sociales que le llevan a ser agente de negocios de Indias en los Cinco Gremios Mayores de Madrid y, más tarde, de la Dirección General de Rentas, desde donde salta a la tertulia fernandina. Para Galdós, tanto Ostolaza como Ugarte fueron «los primeros cortesanos de su época» ${ }^{28}$.

Forman también parte de la camarilla que describe Galdós el marqués de Mataflorida y Pedro Collado, alias Chamorro, antiguo aguador de la fuente del Berro que se distinguió por obtener apetecibles puestos y cargos para sus protegidos, gracias a su cercanía al rey ${ }^{29}$; Antonio Moreno, peluquero elevado a la consejería de Hacienda como galardón por haber copiado a mano el decreto de 4 de mayo de 1814 que dejaba suspensa toda la obra legislativa liberal de las Cortes gaditanas, simbolizando la vuelta al estado de cosas tal y como se encontraban en 1808; y, finalmente, el duque de Alagón, que el escritor canario presenta como acompañante del rey en sus aventuras amorosas por los barrios bajos de la capital — sugiriendo que hace de alcahuete- y uno de los cortesanos más hábiles a la hora de conseguir honores y beneficios:

A los veinte pescó una encomienda de Santiago, y luego fueron cayéndole los grados, no atropelladamente y sin motivo como los cazan estos que se elevan por el favor y la torpe intriga, sino despacito y en solemnidades nacionales como un besamanos, el parto de una reina, los días del Rey y otras fiestas de gran regocijo público y privado ${ }^{30}$

Además, el lector del Episodio lee que el rey concedió al duque de Alagón y otros individuos el privilegio de comerciar con harinas en la isla de Cuba con buques bajo bandera extranjera, lo cual les reportaba enormes beneficios. Para explotar ese lucrativo negocio, el noble cortesano se asoció con el barón de Colly, un aventurero del cual no se conocía su nacionalidad y que había intentado organizar la fuga de Fernando VII de Valençay durante la guerra contra el francés ${ }^{31}$. Nombrado el duque, además, capitán de los guardias del monarca, Galdós recogió la leyenda de que, mientras al ejército y a la armada todo le faltaba, esos

\footnotetext{
28 Pérez Galdós, 1884a, p. 250.

${ }^{29}$ Se podría ligar este personaje con los derivados por el fenómeno cultural del casticismo que triunfó a comienzos del siglo XIX, y que el propio Galdós tuvo en cuenta a la hora de escribir otro Episodio Nacional, el que retrata la corte del padre de Fernando VII, como analiza González Martín, 2019, pp. 524-536.

30 Pérez Galdós, 1884a, p. 259.

${ }^{31}$ La vida de este aventurero y de esos intentos de rescate han sido analizados por Franco de Espés, 2019.
} 
soldados recibían enormes sumas de dinero, de las que nada se comunicaba a Hacienda ${ }^{32}$.

Sin embargo, la documentación que se encuentra en el Archivo General de Palacio parece poner más que en duda esa visión galdosiana, al encontrarse cartas del duque de Alagón a sus familiares en puestos destacados de la Real Casa donde se muestra con constantes problemas económicos y se queja de la aparente indiferencia que le muestra el rey ${ }^{33}$. Su misma esposa, María del Pilar Silva y Palafox, grande de España de primera clase, condesa de Castelflorido, solicitó a Fernando VII su nombramiento como camarera mayor con sueldo en 1819, ante las dificultades económicas por las que atravesaba su casa. El monarca no actuó arbitrariamente, sino que consultó la petición con su mayordomo mayor, el conde de Miranda, el cual requirió un informe del contador mayor. Como se observa, la corte había acentuado su carácter como maquinaria administrativa desde las reformas borbónicas del siglo XVIII. Los funcionarios palatinos, finalmente, tras una larga exposición argumentada llegaron a la conclusión de que la duquesa de Alagón había sido nombrada dama de la reina sin sueldo, como la duquesa de San Carlos, en 1815, y no podía aspirar al elevado cargo de responsabilidad que solicitaba. La duquesa de Alagón solo logró sueldo como dama cuando pasó de supernumeraria a titular, por fallecimiento de quien se encontraba ejerciendo el cargo en esos momentos, la condesa de Buñuel ${ }^{34}$. Al favoritismo del rey resulta necesario, en consecuencia, ponerle límites.

En cuanto a Chamorro, teniendo en cuenta la costumbre del rey de solazarse con hombres ingeniosos, no resulta extraño que aceptase a quien había sido un criado fiel en tiempos de Godoy y de su exilio en Francia, ya que disfrutaba de sus salidas y de los chismorreos o noticias que le comunicaba de las secciones más bajas de la Real Casa. No obstante, Fernando VII siempre supo diferenciar ambientes y situaciones, sobre todo para evitar la creencia de estar manejado por un valido y, además de baja condición social.

Pensar que todos los personajes que formaron parte del círculo de amistades del monarca actuaron conjuntamente para ejercer una ascendencia sobre el mismo y conducirle hacia una postura determinada, resulta una conclusión poco admisible. En su correspondencia privada con sus hermanos, los infantes don Carlos y don Francisco de Paula, Fernando VII nunca mencionó ni a Chamorro, ni Alagón, ni a Ostolaza ni a Ugarte, salvo algunas ocurrencias satíricas de Ramírez de Arellano. Tras el Trienio Liberal, tampoco volvió a recordarlos en

\footnotetext{
32 Pérez Galdós, 1884a, p. 260.

${ }^{33}$ Carta del duque de Alagón al conde de Miranda, mayordomo mayor, 27 de marzo de 1819. Archivo General de Palacio, Expedientes Personales (en adelante, AGP, EP) 26/I.

${ }^{34}$ AGP, EP, 26/2.
} 


\section{ANTONIO MANUEL MORAL RONCAL}

sus cartas a sus hermanos y cuñadas ni a su guardasello, Juan Miguel de de Grijalva ${ }^{35}$.

Incluso Galdós presentó, en su relato, la ineficacia de algunas maniobras de los camarilleros. Ugarte y el duque de Alagón, compradores de juros - deuda pública- al 2 \%, maniobran para colocar a Pipaón al frente de la Caja de Amortización de Hacienda para lograr, de forma corrupta, que la Corona los comprara por un precio más alto o aumentara su valor. Sospechando la maniobra, el ministro Villamil frena ese nombramiento, lo que motiva a los cortesanos a lograr la caída del titular de Hacienda por Felipe González Vallejo, candidato también del infante don Antonio y un hombre sencillo y maleable. $Y$ es que los miembros de la Camarilla se enfrentan por el poder con los miembros del gobierno que, sin embargo, no son descritos de forma más clemente por Galdós. No obstante, cabe subrayar el hecho de que el novelista canario criticó tanto las carencias del liberalismo como los abusos del absolutismo, defectos ambos de una clase política que no supo en ningún momento afrontar los graves problemas que azotaron a España durante el reinado de Fernando VII.

\section{MINISTROS Y CORTESANOS}

La corte reunía dos esferas: por una parte, la propiamente doméstica, ligada a la familia real $y$, por otro, la política-administrativa, al reunir también al gobierno, sus secretarías y archivos en el mismo edificio. Ambos ámbitos tenían vasos comunicantes y participaban, en ocasiones, de una cultura común. Durante el siglo XIX se produjo un movimiento de separación —no solo simbólica y legislativa sino física - entre ambas esferas, ante el empuje de la revolución liberal. Galdós describe a los ministros, por ello, en pasillos, antecámara y cámara del palacio real, conviviendo con los miembros de la jerarquía cortesana. $Y$ siempre obsesionados con evitar que los nombramientos y prebendas no fueran controlados por ellos sino por sus oponentes de la camarilla ${ }^{36}$.

El ministro de la Guerra, general Eguía, cruzado de los absolutistas, es ridiculizado en Memorias de un cortesano por su peluca de coleta, antigua y evidente muestra de su posicionamiento político y de su deseo porque nada - ni siquiera la moda- mutara desde 1808. Su nulidad como militar es recordada por su retirada de efectivos en la derrota de Ocaña frente a los franceses y por su eficacia en la represión contra los liberales al final de la guerra ${ }^{37}$. Pedro Ceballos, ministro

${ }^{35}$ AGP, reinado de Fernando VII, cajs. 25, 27 y 28.

${ }^{36}$ Así lo señala el propio Pipaón. Pérez Galdós, 1884a, p. 254.

37 Pérez Galdós, 1884a, pp. 194-196. 
de Estado, que tuvo la capacidad de adaptarse pragmáticamente a todos los cambios dinásticos y políticos de los últimos diez años, surge de la pluma de Galdós como un corrupto, enemigo declarado de la camarilla. Por su parte, el ministro de Justicia, Tomás Moyano, es descrito como altamente insignificante en su labor, aunque con habilidad suficiente para colocar a miembros de su amplia familia en la administración. Sin estudios de ninguna clase, afirma Galdós, Juan Estaban Lozano fue un caso único en la historia de los titulares de la cartera de Gracia y Justicia, cuyo escaso carácter fue subrayado por el hecho de estar dominado domésticamente por un ama de llaves, empeñada en que todas las mitras de la Monarquía católica fueran ocupadas por sus familiares ${ }^{38}$. El ministro de Hacienda, Juan Pérez Villamil comunica al rey, con toda sinceridad, la realidad del momento: crisis, falta de dinero, reino sin recursos y los territorios americanos sublevados, por lo que se necesitaba «hombres, dinero y barcos». Por ello, el rey exige un plan para conseguir dinero y acabar con la rebelión de las Américas, pero será Ugarte quien logra el apoyo de Fernando, al ofrecerle la adquisición de una flota con el dinero que los británicos habían facilitado para indemnizar a los traficantes de africanos, tras la prohibición del comercio de esclavos. A cambio exige la caída de Villamil para lograr introducir en Hacienda a sus peones ${ }^{39}$.

Frente a esta visión esperpéntica, la historiografía ha procurado describir una realidad política. Aparentemente, el reinado de Fernando VII no conllevó un cambio de vertiente en el organigrama de la elite política ministerial respecto a épocas anteriores. Ni en sus principios ideológicos ni en su función, ni siquiera en la edad media de sus componentes, unos cincuenta años. Tampoco en el destierro que muchos de ellos tuvieron que afrontar, ya que, si hay ejemplos en la centuria ilustrada, abundaron en esta época, y no solo entre los colaboradores del hermano de Napoleón sino también ministros de las etapas constitucionales y aun absolutistas, como Calomarde o el conde de Alcudia. Pero las pruebas de estar asistiendo a un fin de etapa y el comienzo de una nueva fueron abundantes. Los miembros del gobierno, como en el siglo anterior, fueron ante todo servidores de la Corona, sin excesiva especialización en su formación y función. Provinieron del campo administrativo, de la magistratura, la abogacía y el mundo castrense. Necesariamente, las secuelas de un reinado envuelto en guerras de larga duración y pronunciamientos se hicieron notar, cooperando la milicia te-

\footnotetext{
${ }^{38}$ El literato canario insiste en integrar los obispados en el saco de ambiciosos puestos que todos los cortesanos y políticos deseaban controlar a través de su influencia en el rey. Anteriormente, escribe que Blas Ostolaza pretendió una mitra, «por la cual bebió vientos y tempestades en las antecámaras de palacio», Pérez Galdós, I884a, p. 220.

39 Pérez Galdós, 1884a, pp. 321-332.
} 


\section{ANTONIO MANUEL MORAL RONCAL}

rrestre con un $28,41 \%$ del conjunto de ministros. Treinta y tres ministros militares se encargaron del despacho de Guerra, cuatro de Marina, dos de Hacienda, cinco de Estado, cinco de Gobernación, así como dos asumieron funciones en las Juntas Supremas y ocho en las Regencias. Si el porcentaje del Ejército como proveedor de elites ministeriales fue importante en este reinado, la Marina aportó veintiún ministros, un II,93\% del total, secundando al primero en la dirección de otros departamentos: dos en Estado y Hacienda, uno en Gobernación y tres en el de Guerra, produciéndose un intercambio entre ambas carteras militares. $\mathrm{Si}$ en las Juntas su número resultó muy exiguo, aportaron sin embargo cinco miembros en las Regencias, durante la guerra de la Independencia. La busca de estrategias para fortificar a una herramienta vital de un Imperio ultramarino en plena crisis puede revelar esa significativa presencia de marinos ${ }^{40}$.

Mayor presencia en los gobiernos fernandinos que en reinados anteriores tuvieron veintiún diplomáticos, siguiendo al grupo de funcionarios - treinta y tres- que coronaron su carrera en los sillones del poder ejecutivo. Si en reinados anteriores la magistratura había aportado varios ministros, ahora su número se disparó hasta veintitrés, mientras el clero proveyó seis, por última vez. Esta miscelánea de tradición y novedad se reforzó con la aparición en los equipos ministeriales de otro tipo de profesionales como seis profesores y cuatro catedráticos, más un director de estudios de San Isidro; nueve abogados, un fiscal, cuatro banqueros, tres comerciantes, tres jurídicos militares y un ingeniero de minas completaron el recuento.

Indudablemente, los miembros del gobierno y los altos funcionarios trataron de mantener su lugar de preeminencia en la corte, tanto en Madrid como en los Sitios Reales, vigilando el cumplimiento del protocolo. Sin embargo, muy pocos altos cargos cortesanos fueron nombrados miembros del gobierno o de las juntas, y ningún secretario o ministro fue designado para ocupar un puesto de responsabilidad en el organigrama de la Real Casa durante el reinado de Fernando VII. La mayor parte de los cortesanos que apoyaron al rey en su época de príncipe de Asturias -en sus conspiraciones contra Godoy- continuaron su carrera dentro de la servidumbre palatina ${ }^{41}$. $Y$ es que la buena marcha de la corte exigía trabajo y responsabilidad. El mayordomo mayor, el sumiller de corps, la camarera mayor, el caballerizo mayor, los veedores generales y sus inmediatos subalternos debían hacer frente a los problemas diarios del ámbito cortesano meramente doméstico. La corte era la muestra del poder y de la dignidad de la Corona y, aun para los embajadores europeos, el símbolo manifiesto de la pujanza de la

\footnotetext{
${ }^{40}$ Así se demuestra en Moral Roncal, 2019, pp. 167-192.
}

${ }^{41}$ La Parra, 2007, pp. 255-267 y 2010, pp. I27-152. 
Monarquía: la maquinaria cortesana debía funcionar apropiadamente. No resultaba conveniente que, ante esas circunstancias, se les acrecentaran responsabilidades propias del gobierno del reino, aunque el mayordomo mayor formara parte, en algunos momentos, del Consejo de Estado. Fernando VII nombró persistentemente para estas servidumbres a nobles de su confianza que, en caso de perderla gravemente, eran reemplazados y expulsados de palacio. Muy pocos de los cortesanos de su juventud lograron el sillón ministerial, salvo las excepciones del duque de San Carlos ${ }^{42}$ y Pedro de Ceballos ${ }^{43}$, ambos en la secretaría de Estado.

Y pese a leyendas exageradas respecto a la presencia de la camarilla en la vida política, frente a los ministros, Galdós reconoce la autonomía de Fernando VII en la toma de decisiones, así:

En las tertulias de S. M. nadie podía vanagloriarse de tener ascendiente absoluto y constante. Unos días privaba este, otros aquel, según las voluntades recónditas y jamás adivinadas de un monarca que debiera haberse llamado Disimulo ${ }^{14}$.

Efectivamente, no parece que el rey tuviera un favorito claro, pues pesaba demasiado en su memoria el nefasto recuerdo de Manuel Godoy en su adolescencia y juventud. Por ello, Fernando VII pudo tener íntimos en la corte, incluso algunos decisivos como Juan Miguel de Grijalva ${ }^{45}$, pero los historiadores certifican esa capacidad de decisión del monarca durante la mayor parte de su reinado.

El tema de las camarillas fue aludido también por Galdós en su siguiente episodio nacional, La segunda casaca, ambientada en los últimos años del sexenio absolutista (I8|4-|820), previos al trienio liberal donde se pondría en vigencia,

42 AGP, EP, 954/2.

${ }^{43}$ AGP, EP, $16.782 / 29$.

${ }^{44}$ Pérez Galdós, I884a, p. 333. El novelista recalca más la nulidad de los cortesanos que el dominio que pretendidamente creen poseer sobre la voluntad del monarca. A Galdós le interesa especialmente mostrar la podredumbre moral de unos políticos y consejeros que eliminan todo tipo de honor y mérito, premiando en cambio a pícaros y embusteros. El empleo continuado de la ironía, sin embargo, degrada el texto a la condición de farsa, reflejo en último lugar del desengaño del escritor frente a un Sexenio Revolucionario que prometió mucho más de lo que luego fue capaz de edificar, como sugiere Dorca, 2017, p. 274.

45 Juan Mlguel de Grijalva (I766-1833), que ha sido considerado uno de los hombres de confianza de Fernando VII. Comenzó su carrera como ayuda de Cámara, para ascender a la jefatura del Guardajoyas, de la Tapicería y de Furriera, llegando a ser aposentador mayor en vísperas de la guerra de la Independencia. La Regencia le nombró secretario de Cámara y Real Estampilla, cargo en el que se mantendría hasta el final del reinado. Su función sucedía a la desarrollada, anteriormente, por el antiguo guardasellos, pues se autorizaba con la estampilla todos aquellos documentos de las secretarías y ministerios que el rey no firmaba de su propia mano. Fue un importante eslabón que unió palacio con la administración pública en materia de tramitación de expedientes. Grijalva, fiel fernandino, cuñado del marqués de la Roca, apoyó la sucesión femenina desde su alta posición a fines del reinado. AGP, EP, 480/I3. 


\section{ANTONIO MANUEL MORAL RONCAL}

nuevamente, la obra de las Cortes de Cádiz. Pipaón alude a la intervención de la segunda esposa del rey ${ }^{46}$ :

Mientras reinó Isabel, la influencia política de los criados mermó mucho en palacio y este fue lo que debía ser, una vivienda de reyes; pero desde diciembre del 18 , en que Dios se la llevó de la tierra a la insigne princesa, las culebras de la camarilla volvieron a recuperar su imperio. (...) Ramírez de Arellano y un tal Villar Frontín, antiguo escribano del resguardo, eran los que se comían el reino crudo ${ }^{47}$.

Pese a todo, Fernando VII procuró siempre informarse, por varias vías, de todos los asuntos, y en muchos casos por sí mismo, para tomar la decisión que personalmente considerara oportuna. Solicitó en muchas ocasiones informes, dictámenes y memorias sobre las cuestiones de gobierno y de su propia casa, que después estudiaba detenidamente, antes de llegar a una conclusión, que solía escribir al dorso de algunos documentos con su letra pequeña y clara. Por ejemplo, entre 1816 y 1820 no asumió ninguna decisión sobre la petición de la Junta de Grandes sobre restablecimiento de los señoríos jurisdiccionales mientras no llegaran las consultas realizadas a consejos y tribunales, de tal manera que numerosos grandes desistieron de sus esperanzas de lograr esa restauración ${ }^{48}$.

Por otra parte, Galdós señala, en boca de uno de sus personajes, el enorme gasto que supone el mantenimiento de la corte: «Yo calculo que Su Majestad, arreglándose a la mayor sobriedad posible, no habrá gastado en el año que acaba de transcurrir, arriba de ciento veinte millones» ${ }^{49}$. Sin embargo, la cifra se encuentra totalmente exagerada. El 22 de mayo de 1814 el monarca ordenó la separación de la Real Casa de la administración del Estado - como había prometido en su decreto de 4 de mayo-y la centralización de poderes en el mayordomo mayor, pues anteriormente los asuntos de la Real Casa se encontraban distribuidos entre varias secretarías de Estado. Además, Fernando VII decidió aceptar la consignación anual de 40 millones de reales, tal y como habían acordado las Cortes de 19 de abril de ese mismo año, lo que mantuvo durante todo su reinado. Creyó que, unido ese dinero al generado por sus propiedades particulares, se cubrirían anualmente los gastos, pero no fue así. Las rentas de esos bienes fueron sobrevaloradas en su momento, como en poco tiempo los tesoreros y contadores regios advirtieron. En 1818, las rentas de los Reales Sitios no alcanzaban ni para cancelar sus deudas, no sobrepasando la cifra de 5 millones de

\footnotetext{
${ }^{46}$ Esta visión positiva de la reina Isabel de Braganza se añade a otros gestos de la soberana que conformó un discurso positivo de su figura. A falta de una gran biografía, una aproximación a su figura es la Calvo Maturana, 2010, pp. 13-38.

${ }^{47}$ Pérez Galdós, 1884b, p. 26.

${ }^{48}$ Como se concluye en Moral Roncal, 2020a, pp. I59-19|.

${ }^{49}$ Pérez Galdós, 1884a, p. 33.
} 


\section{REALIDAD Y FICCIÓN EN EL EPISODIO GALDOSIANO}

reales en el año más próspero. Por eso, se intentó impulsar un plan severo de ahorro y, aprovechando la apertura de Cortes en 1820, el tesorero general sugirió al rey que solicitase un aumento hasta la cifra de 50 millones, número que debía aproximarse mejor a los gastos totales anuales de la Real Casa y Patrimonio, y no los 120 millones que alude Galdós. Sin embargo, el consultor general de la misma se manifestó contra esa petición, pues según la constitución la cantidad se ajustaba en el inicio del reinado y no se podía alterar durante su duración, además de lo impopular que resultaría en aquellos momentos, cuando la situación económica no era próspera ${ }^{50}$.

\section{EL BESAMANOS: UNA CEREMONIA CORTESANA}

A partir de 1814, la Casa Real restauró el conjunto de ceremonias que habían sido tradicionales en la corte de Carlos IV, eliminando las impuestas durante la ocupación francesa, llegando al detalle de descartar incluso nombres en francés de algunos cargos internos. Entre las mismas, se volvieron a organizar los besamanos, solemnidades donde se demostraba la lealtad a la familia real por parte de los invitados al acto ${ }^{51}$. La Camarería Mayor y la Mayordomía Mayor participaron en la organización de los besamanos en los Reales Sitios, los cuales podían ser de varias clases. Por una parte, los de Cámara donde acudían solamente los altos cargos de la corte y oficios en propiedad, ya que los supernumerarios podían solicitar su presencia en el besamanos general. Por otro, los llamados besamanos generales, a los que asistían personas sin servidumbre asignada que lo solicitaban a mayordomía mayor o a la camarería mayor con antelación. Además, cuando algún miembro de la familia real visitaba un pueblo o ciudad, las autoridades locales organizaban besamanos para demostrar la fidelidad de su población, a través de sus representantes sociales más distinguidos. En el reinado

${ }^{50}$ Archivo Histórico Nacional (AHN), Diversos, Reales Cédulas, $n^{\circ}$ 2.194. AGP, reinado de Fernando VII, 330/29, memoria sobre el aumento de dotación de la Casa del Rey, realizada por Pedro Sáinz Terrones, tesorero de la Real Casa; archivo infante don Gabriel, secretaría, leg. 767. Incluso desde principios de mayo de $18 \mid 4$, las pensiones y rentas eclesiásticas de la Real Capilla se unificaron en la tesorería general de la Real Casa, incrementando el control sobre gastos e ingresos, como analiza Onsurbe Plaza, 2018, pp. 160-161.

${ }^{5 I}$ Todavía a finales del siglo XIX se definía esta solemnidad de la corte como una concurrencia de los dignatarios del Estado, autoridades, cuerpos y personas que tenían entrada en tal acto para rendir homenaje a la familia real. En las capitales de provincia donde el rey no recibía personalmente por estar ausente, organizaban el besamanos las autoridades provinciales, pero sin besar la mano del dignatario principal. Martínez Alcubilla, I868, II, p. 723. 


\section{ANTONIO MANUEL MORAL RONCAL}

de Fernando VII fueron multitudinarios los que se organizaron durante sus trayectos a Andalucía (1823) y Cataluña (I827 y I828). Se trataba de refrendar la legitimidad popular de la Monarquía, como Emilio La Parra ha subrayado ${ }^{52}$.

Efectivamente, a pesar de la crítica y demoledora descripción que hace Galdós del monarca en este episodio, lo cierto es que Fernando VIl intentó siempre mostrarse próximo a sus súbditos, incluso amable. Ante todo, lo sintieron como cercano aquellos españoles que le observaron paseando por Madrid y por las ciudades que visitó durante sus viajes, en las corridas de toros, en el teatro, en los besamanos y audiencias públicas. No debe olvidarse que el rey recibía en palacio a la gente más diversa los jueves y los domingos, derrochando campechanía ${ }^{53}$. Con mayor intensidad la mostraba ante personas recomendadas por sus amigos, como se aprecia en el trato que Pipaón recibe del rey en su tertulia ${ }^{54}$.

Galdós describe un besamanos que se organizaba también durante las visitas de la familia real a lugares de especial significación religiosa. En Memorias de un cortesano de 1815 lo sitúa en el convento madrileño de los trinitarios descalzos o de la Santísima Trinidad, el cual, durante la Guerra de Independencia, los franceses habían organizado su exclaustración, siendo utilizado como sede de la Real Biblioteca Pública. Fernando VII devolvió el convento a los monjes trinitarios, por lo que se mostraron muy agradecidos, recibiéndole con gran solemnidad como describe Galdós ${ }^{55}$. La comitiva regia provoca la exaltación patriótica de Pipaón que no duda en señalar que «parecía que le transportaban a uno al Oriente o a las pomposas fiestas de la India» ${ }^{56}$, palabras a través de las cuales el escritor liberal compara el concepto monárquico absolutista con los despotismos orientales o asiáticos, en la terminología y concepto de la época. Además, simbolizaba para la óptica liberal no la devoción religiosa de la familia real sino la unión del Trono y el Altar. Sin embargo, para quienes veían una clara utilidad en estas ceremonias, como Pipaón, a través de ellas se apreciaba «la grandeza nacional, sus tesoros, su dignidad, la representación más admirable de su gran poderío» ${ }^{57}$. $Y$ es que el tono informal y cotidiano con que el rey abordaba los asuntos de Estado en sus tertulias se transforma en solemnidad en el instante de presidir una ceremonia reli-

52 El propio rey ordenaba escribir, en sus diarios, el número de los participantes en esos multitudinarios besamanos, lo que demuestra su interés por los mismos. Sevillano Calero y Soler Pascual, 2013.

53 La Parra, 2018, p. 18 y ss.

54 Pérez Galdós, 1884a, pp. 235-240 y 307 y ss.

55 El convento de la Trinidad también fue objeto de interés de otros escritores, como la Duquesa de Abrantes 2016, p. 175. Original editado en francés en 1837.

${ }^{56}$ Pérez Galdós, 1884a, p. 287.

57 Pérez Galdós, 1884a, p. 288. 


\section{REALIDAD Y FICCIÓN EN EL EPISODIO GALDOSIANO}

giosa. Viéndole arrodillado en actitud edificante, escuchando con atención el sermón del padre y orando con devoción, los asistentes a la eucaristía son descritos por Pipaón como testigos conmovidos profundamente por esa situación.

Entre las damas conocidas por Pipaón, acuden al besamanos de los trinitarios la condesa de Rumblar y su hija, además de las señoras de Porreño. Y es que la alta presencia femenina es una clara veracidad histórica, no una invención literaria para ayudar al desarrollo de la trama. Efectivamente, fue muy numerosa la presencia de mujeres en los besamanos organizados por la Casa Real, tanto en palacio como fuera del mismo. Acudían damas que, por su situación social, debían ser vistas para evitar perder su distinción, como aristócratas, pero también por la situación profesional de sus maridos, hijos o hermanos, como esposas de altos funcionarios de la corte, de la administración, del ejército o la armada. En el caso de las viudas, su presencia evitaba el olvido, subrayaba su estatus social y, tal vez, facilitaba alguna pensión o ayuda. Otras mujeres acudían para agradecer personalmente al rey haber distinguido de alguna manera a sus parientes; las grandes o esposas de grandes también asistían para mostrar su interés por formar parte de la servidumbre femenina de la reina en un futuro cercano ${ }^{58}$. $Y$ tanto las mujeres como los hombres que participaban en esas ceremonias rituales advertían que su presencia en las mismas engendraba una alianza, una totalidad, una comunidad que podía ayudarles en su supervivencia diaria. Una presencia que debía repetirse - de ahí sus intentos por ser admitidos en otros besamanos- ya que era rasgo esencial de los rituales, generando intensidad ${ }^{59}$.

Todas esas motivaciones convergen en las damas descritas por Galdós, a las que el prior de los trinitarios había prometido que podrían «hablar con Su Majestad y entregarle nuestros memoriales ${ }^{60}$. Efectivamente, se ha comprobado esa costumbre en los besamanos, donde, al ser presentadas al personaje regio, se permitía que le solicitaran su atención sobre un asunto expuesto en un papel llamado memorial. Se trataba de un recurso que las mujeres de la época aprovecharon para tratar de mejorar su situación personal o la de sus familias. En la narración, la condesa de Rumblar solicita una bandolera - es decir, un puesto de oficial en el ejército- y las señoras de Porreño una moratoria en el pago de una deuda que tenían sobre unas tierras de su linaje y que habían contraído con el

${ }^{58}$ Así se desprende del estudio de la documentación de Camarería Mayor en AGP, AD, cajs. 22.855-22.859, expedientes relativos a asistencia a galas y besamanos (I8I4-1867). Sobre esta sección femenina de la corte me remito al trabajo de Moral Roncal, 2020b, pp. I39-167.

59 Han, 2020, PP. 17-27. La importancia del rito en la sociedad contemporánea del siglo XIX es continuación de una larga tradición de civilización, en crisis aparente a comienzos de la actual centuria. Sin embargo, sus estudios se han relanzado por su interés sociológico y cultural como se desprende de los trabajos reunidos en Barrios y Alvarado, 2020.

60 Pérez Galdós, I884a, p. 285. 


\section{ANTONIO MANUEL MORAL RONCAL}

banquero Grijalva. La petición de estas últimas no es aprobada por el rey, por influencia de Pipaón el cual logra engañar a Grijalva para que le venda, por la mitad de su valor, la deuda de las Porreño a cambio de prometer la libertad de su hijo Gaspar, encarcelado por insultar al monarca. Pese a que ha hecho todo lo posible por mantener su encarcelamiento, Gaspar sale de la prisión, aunque Pipaón logra ser un terrateniente aun a costa de dejar en la miseria a sus antiguas amigas, las señoras de Porreño. Fortalece, con ese tipo de adquisición, su imagen como caballero, como «noble», según los usos culturales de la época.

\section{FINAL EN UN SITIO REAL}

La Real Casa de Campo fue el escenario cortesano que eligió Galdós para finalizar este Episodio Nacional. Fue creada por Felipe II que formó una finca que unió a su alcázar madrileño con el cazadero de El Pardo, y alrededor de este núcleo se fueron añadiendo tierras de labor y campos adquiridos a los colindantes. Sus sucesores lo declararon Bosque Real. Teniendo en cuenta su finalidad cinegética y campestre, ante la proximidad de palacio, aquella que fue primitiva casa de campo de los Vargas se extendió para amparar aposentos reales para estas funciones. Carlos III ordenó que se practicara allí también la ganadería y la agricultura, formando parte del Patrimonio Real y, por lo tanto, siendo necesario a los particulares solicitar un permiso a su administrador para pasear por la Casa de Campo, como hace Pipaón ${ }^{61}$.

Ejemplo de cortesano corrompido por su acercamiento a otros, el protagonista de estas memorias intenta imitar - io suplantar? - al duque de Alagón, al que Galdós trata como alcahuete. Si las damas de Porreño le habían cerrado las puertas de su casa, no así la condesa de Rumblar ni su hija Presentación, novia de Gaspar, que desea agradecer a Pipaón sus supuestas maniobras cortesanas que han facilitado su liberación final. Como este se ha dado cuenta del interés que ha despertado la muchacha ante el rey - durante una escapada nocturna en Madrid y durante el besamanos en los trinitarios ${ }^{62}$ - intenta convencer a Presentación de que vaya a un encuentro con el monarca en la Casa de Campo, que parezca fortuito. Siguiendo las costumbres de la época, Pipaón sugiere que les

${ }^{61}$ Galdós insiste constantemente en que en la administración regia impera el capricho y no el mérito, al señalar que el administrador de la Real Casa de Campo es un pinche de cocina que se ganó al monarca cuando era príncipe de Asturias denunciando supuestos intentos de envenenamiento de sus comidas. Pérez Galdós, 1884a, p. 358. Visión muy debatida por la historiografía sobre la corte, como anteriormente se ha señalado.

62 Las inclinaciones amorosas del monarca convierten las referencias de Pipaón a su bondad paternal en una broma sobre la corrupción moral del régimen absolutista. El hecho de que el protagonista intente luego aprovecharse de las inclinaciones de Fernando VII para fomentar su propio ascenso político, hace sospechar al lector sobre el nivel de autoconciencia del narrador, como señala Espejo Saavedra, 2003, p. 94. 
acompañe su hermano, el cual también se muestra agradecido por haber conseguido su bandolera.

Una vez allí, se suben a una barca en el lago y Presentación tira al agua a Pipaón delante de Fernando VII y su séquito, que se ríen del suceso. $\mathrm{Ni}$ ella ni su hermano habían sido engañados pues deseaban vengarse de quien tan mal se había portado con su círculo de amistades. El cortesano queda ridiculizado, siendo el peor castigo para su imagen en esa microsociedad. Quien creía que era el único que dominaba a los demás, su última aventura le demuestra los límites de su propia capacidad de descifrar y fiscalizar la realidad. Convertido en distracción y chanza de los cortesanos que paseaban por la Casa de Campo, Pipaón queda envuelto en una apostilla irónica sobre las presunciones de poder y persistencia del régimen fernandino. Termina la narración con la vuelta precipitada del rey a palacio al conocerse la vuelta de Napoleón a Francia desde su exilio en la isla de Elba.

\section{CONCLUSIÓN}

De la boca de Gabriel, el protagonista de la primera serie de los Episodios Nacionales, que aparece en un momento hablando con Pipaón, Galdós expuso su idea $-y$ la de toda la cultura liberal de su época - sobre la existencia del cortesano:

El alma se debate, el corazón se oprime al considerar aquel vacío inmenso, aquella ruin y enfermiza vida, que no tiene más síntomas visibles en la exterioridad de la Nación que los execrables vicios y las mezquinas pasiones de una corte corrompida. No hay ejemplo de una esterilidad más espantosa, ni jamás ha sido el genio español tan eunuco ${ }^{63}$.

Sin embargo, la estructura cortesana sobrevivió al huracán revolucionario. $Y$ es que la corte era un extracto de todo el reino, al reunir una población de orígenes sociales y geográficos variados: nobles de viejos linajes se codeaban con nuevos títulos y caballeros de órdenes militares; hidalgos aspiraban a ocupar algún cargo en la Real Casa y Patrimonio disputándoselo a alguna persona de orígenes más humildes pero perteneciente a una familia tradicionalmente servidora de la Corona durante decenios; americanos se codearon con peninsulares en la corte de Fernando VII quizá como en ninguna época de la historia anterior; los ministros, magistrados y consejeros se encontraban en las antesalas con personajes de todos los ámbitos sociales. Así lo retrató Galdós, pero con una mirada

63 Pérez Galdós, 1884a, p. 335-336. 
crítica, destructora, más que complaciente de esa realidad histórica —la sociedad cortesana- que quizá nunca comprendió.

Los besamanos, por ejemplo, tan ligados a la cultura cortesana fueron rechazados por el escritor canario, sin comprender que era un rito con una clara acción simbólica. Trasmitía y representaba valores y órdenes que mantenían cohesionada a una comunidad. Al ser una forma de reconocimiento, la percepción simbólica advertía lo duradero de una sociedad cortesana que no deseaba morir. El mundo era liberado de su contingencia y se le otorgaba una permanencia. Esos rituales otorgaban, además, una estabilidad a la vida de muchos de los seres humanos que aceptaban su permanencia. No obstante, Galdós no podía rechazar - como así se aprecia en sus obras - que sus personajes mantuvieran otro tipo de rituales ligados a la cortesía, que posibilitaba un buen trato sino también un pulcro y respetuoso manejo de las cosas.

La corte fue una noria social: el cortesano podía ascender y descender con la misma facilidad, sobre todo por cambios políticos que caracterizaron este reinado o por no cumplir con las expectativas de eficacia puestas en su figura. La buena marcha de la Real Casa exiǵa profesionalidad, aunque se ligara a la gracia del monarca, de ahí la necesidad también de contar con buenos especialistas en cada una de las ramas de la administración cortesana. Existían en la corte dos jerarquías: la establecida por la norma, que fijaba puestos y deberes que debían asumir desde el mayordomo mayor hasta la última barrendera; $y$ la efectiva, determinada por el favor del rey o el poder de alguna persona cercana, a su vez cambiante y no institucionalizada. Galdós presenta una visión parcial, al referirse tan solo a esta última mediante Pipaón y sus amigos de la camarilla, a la que la cultura política liberal culpabilizó de todos los males de España de forma totalmente exagerada. Pero Galdós temía su repetición quizá -como en la época de Isabel II- y por eso, en plena restauración de Alfonso XII, tal vez intentó avisar del peligro que estos grupos cortesanos conllevaban para la imagen pública de la familia real y de la propia Monarquía constitucional. En todo caso, ni el monarca ni su viuda, la regente María Cristina de Habsburgo-Lorena, mantuvieron camarilla alguna, librándose de ese crítico lastre.

\section{BIBLIOGRAFÍA}

Alarcón Alarcón, María del Mar, «Las relaciones entre la Corona y la aristocracia española durante el reinado de Carlos IV: el caso del XIII duque del Infantado (I79I-1808)», Pasado y Memoria, II, 2012, Pp. 165186.

Altuve-Febres, F., «Blas de Ostolaza, un apasionado de la fidelidad», Anales de la Fundación Elías de Tejada, 13, 2007, pp. |4|-163.

Álvarez Junco, José y Gregorio de la Fuente, El relato nacional. Historia de la historia de España, Madrid, Taurus, 2017.

Ayuso, Miguel, «El pensamiento político del manifiesto de los persas», Aportes. Revista de Historia contemporánea, 87, 2015, pp. 5-33. 


\section{REALIDAD Y FICCIÓN EN EL EPISODIO GALDOSIANO}

Baquero Goyanes, Mariano, «Perspectivismo irónico en Galdós», Cuadernos Hispanoamericanos, 250-252, 1970. 1971, pp. 143-160.

Barrios, Feliciano y Javier Alvarado (dirs.), Aires de grandeza. Hidalgos presuntos y nobles de fantasía, Madrid, Dykinson, 2019

Barrios, Feliciano y Javier Alvarado (coords.), Rito, ceremonia y protocolo. Espacios de sociabilidad, legitimación y trascendencia, Madrid, Dykinson, 2020.

Beyrie, Jean, «Transfondo psicológico y fuentes íntimas de la novelística galdosiana: el caso de la segunda serie de los Episodios», Boletín de la Biblioteca Menéndez Pelayo, 63, 1987, pp. 213-232.

Butrón Prida, Gonzalo, «Redefinir rey y soberanía: el retorno de Fernando VII y la agonía del liberalismo», Pasado y Memoria, 13, 2014, pp. 59-78.

Calvo Maturana, Álvaro, «María Antonia de Borbón e Isabel de Braganza: el valor simbólico de las dos primeras mujeres de Fernando VII», Feminismo/s, 16, 2010, pp. I3-38.

Canal, Jordi, «Hijos de la España del siglo XIX: Benito Pérez Galdós, los “Episodios nacionales” y el patriotismo», en Historia de la nación y del nacionalismo español, ed. Antonio Morales, Juan Pablo Fusi y Andrés de Blas, Madrid, Galaxia Gutenberg, 2013, pp. 307-321.

Candel Crespo, Francisco, La azarosa vida del deán Ostolaza, Murcia, Academia Alfonso X, 198I.

Carmona Vidal, José, Aristocracia terrateniente y cambio agrario en la España del siglo XIX. La Casa de Alcañices (I 790-19/0), Ávila, Junta de Castilla y León, 2001.

Carrasco, Adolfo, «EI XIII duque del Infantado, un aristócrata en la crisis del Antiguo Régimen», En la España Medieval, extra-I, 2006, pp. 305-336.

Cuenca Toribio, José Manuel y Soledad Miranda García, «Nobleza y poder ejecutivo en la España contemporánea», Historia contemporánea, 17, 1998, pp. 159-168.

Dash, Raoul W., «Galdós: visión esperpéntica de la historia en Memorias de un cortesano de I8I5», en VI Congreso Internacional Galdosiano 1997, ed. Carmen Yolanda Arencibia Santana y María del Prado Escobar Bonilla, Las Palmas de Gran Canaria, Cabildo, 2000, pp. 280-289.

Daumard, Alfonso, «Noblesse et aristocratie en France au XIX siècle», en Les noblesses européennes au XIX siècle. Actes du colloque de Rome, Roma, Escuela francesa de Roma, 1988, pp. 8I-104.

Dorca, Toni, «La restauración del absolutismo (18|4-1820) en la historiografía liberal decimonónica y los Episodios Nacionales de Benito Pérez Galdós», Cuadernos de llustración y Romanticismo, 23, 2017, pp. 26I276

Duquesa de Abrantes, Recuerdos de dos viajes por España a principios del siglo XIX, Barcelona, Universidad de Lérida, 2016.

Espejo-Saavedra, Ramón, «Perspectivismo y tradición literaria en Memorias de un cortesano de 1815 y La segunda casaca», Hispanic Review, 7I, I, 2003, pp. 89-105.

Franco de Espés, Carlos, Los enigmas de Valençay. Fernando VII y la corte española en el exilio (I808-/8/4), Zaragoza, Prensas de la Universidad de Zaragoza, 2019.

González Martín, Francisco Javier, «Novela histórica y crítica mitográfica en Pío Baroja», Boletín de la Real Sociedad Bascongada de Amigos del País, 50, I, 1994, pp. 73-92.

González Martín, Francisco Javier, «Populismo, nobleza e imagen casticista en La Corte de Carlos IV de Benito Pérez Galdós», en Del siglo XIX al XXI: tendencias y debates, ed. Mónica Moreno Seco, Rafael FernándezSirvent y Rosa A. Gutiérrez Lloret, Alicante, Universidad de Alicante, 2019, pp. 524-536.

Grupo de Estudios sobre la Nobleza, La nobleza española, I780-1953, Madrid, Ediciones 19, 2019.

Han, Byung, La desaparición de los rituales, Barcelona, Herder, 2020.

Hernández Montalbán, Fernando, La abolición de los señoríos en España (/8//-/837), Madrid, Biblioteca Nueva, 1999.

Higgs, David, «Nobres e Aristocratas em França no Século XIX: Aspectos da Historiografia», Penélope. Fazer e desfazer a História, 12, 1993, pp. 87-100.

Hinterhäuser, Hans, Los Episodios Nacionales de Benito Pérez Galdós, Madrid, Gredos, 1963.

La Parra, Emilio, «De la disputa cortesana a la crisis de la Monarquía. Godoyistas y fernandinos en 1806-1807», Cuadernos de Historia Moderna. Anejos, vI, 2007, pp. 255-267.

La Parra, Emilio, «Los hombres de Fernando VII en I808», en Las élites y la revolución de España (I808-/8/4), ed. Armando Alberola y Elisabel Larrisa, Alicante, Universidad de Alicante, 2010, pp. 127-I52.

La Parra, Emilio, «La restauración de Fernando VII en I8|4», Historia constitucional, I5, 20I4, pp. 205-222.

La Parra, Emilio, Fernando VII, Barcelona, Tusquets, 2018. 


\section{ANTONIO MANUEL MORAL RONCAL}

Lida, Clara Eugenia, «Galdós y los Episodios Nacionales: una historia del liberalismo español», Anales Galdosianos, 3, 1968, pp. 61-73.

López Sánchez, Carmina, La mano del rey: el mayordomo mayor en la Casa Real del siglo XIX, Alcalá de Henares, Universidad de Alcalá, 2018.

Martínez Alcubilla, Manuel, Diccionario de la administración española. Tomo segundo, Madrid, Administración, 1868.

Moral Roncal, Antonio Manuel, ;El enemigo en palacio! Afrancesados, liberales y carlistas en la Real Casa y Patrimonio (I8/4-/843), Alcalá, Universidad de Alcalá, 2005.

Moral Roncal, Antonio Manuel, «Reflexiones sobre el anticlericalismo español en la obra de Julio Caro Baroja», Revista de Historiografia. Anejos, I, 2014, pp. 229-239.

Moral Roncal, Antonio Manuel, «La nobleza española en la política y diplomacia durante la Edad Contemporánea», Aportes. Revista de Historia Contemporánea, 89, 2015, pp. 8I-II3.

Moral Roncal, Antonio Manuel, «Los cargos cortesanos en el reinado de Fernando VII: ¿trampolín profesional o resultado de servicios políticos a la Corona?», en Nobles, negociantes, políticos y redes cortesanas (España, 1788-1931), ed. Fernando Sánchez Marroyo, Madrid, Ediciones 19, 2019, pp. 167-192.

Moral Roncal, Antonio Manuel, «Las Juntas y Diputación Permanente de la Grandeza de España (I8I5-1833): un intento de intervención política conjunta de la Alta Nobleza», Historia y Política, 43, 2020a, pp. 159. 191.

Moral Roncal, Antonio Manuel, «La Camarería Mayor en la corte de Fernando VIl: un espacio nobiliario de poder informal y capital simbólico», Hispania, LXXX, 264, 2020b, pp. 139-167.

Mosse, Walter, «Aristocracia y burguesía en la Europa del siglo XIX. Un análisis comparativo», en Las burguesías europeas del siglo XIX, ed. Josep Maria Fradera y Jesús Millán, Madrid, Biblioteca Nueva, 2000, PP. I33168

Mozzarelli, Carlo y Giovanni Olmi (coords.), La corte nella cultura e nella storiografia. Immagini e posizioni tra Otto e Novecento, Roma, Balzoni, 1983.

Navascués, Manuel, «Liberales y absolutistas: personajes novelescos en la segunda serie de los Episodios Nacionales», Revista de Literatura, 49, 1987, pp. 49I-5I0.

Onsurbe Plaza, Maitane, «La Real Capilla de palacio durante la restauración fernandina (I8I4- I8I7)», Libros de la Corte, 17, 2018, pp. 150-168.

Pascual Sastre, Isabel María, «La corte bajo una constitución democrática. La Casa Real en el reinado de Amadeo I», en La cuestión de Palacio. Corte y cortesanos en la España contemporánea, ed. Raquel Sánchez García y David San Narciso (coords.), Granada, Comares, 2018, pp. 263-299.

Pascual Sastre, Isabel María, «La última adaptación del modelo cortesano. Organizando la Real Casa de Amadeo I de Saboya», La Albofalia, 20, 2020, pp. 347-380.

Pérez Galdós, Benito, «Memorias de un cortesano de 1815 », en Episodios Nacionales. Tomo VI, Madrid, Imprenta y Litografía de la Guirnalda, 1884a, pp. 189-367.

Pérez Galdós, Benito, «La segunda casaca», en Episodios Nacionales. Tomo VII, Madrid, Imprenta y Litografía de la Guirnalda, 1884b, Pp. 3-214.

Powis, Jonathan, La aristocracia, Madrid, Siglo XXI, 2007.

Rueda Hernanz, Germán, «La supresión de señoríos y el proceso desvinculador de los bienes nobiliarios», Aportes. Revista de Historia Contemporánea, 89, 2015, pp. 41-58.

Risco, Antonio, «Avatares de la nobleza afrancesada y liberal», en Las élites y la revolución de España (I808-|8/4), ed. Armando Alberola y Elisabel Larriba, Alicante, Universidad, 2010, pp. 187-206.

Sánchez, Raquel (coord.), «Monográfico. La corte como escenario político en España (I833-|885)», Aportes. Revista de Historia contemporánea, 96, 2018, p. I-I8I.

Sánchez, Raquel (coord.), Un rey para la nación. Monarquía y nacionalización en el siglo XIX, Madrid, Silex, 2019.

San Narciso, David y Raquel Sánchez (coords.), La cuestión de palacio. Corte y cortesanos en la España contemporánea, Granada, Comares, 2018.

Sánchez Marroyo, Fernando, Riqueza y familia en la nobleza española del siglo XIX, Madrid, Ediciones 19, 20I4.

Sánchez Marroyo, Fernando, «Las economías nobiliarias en el siglo XIX. El protagonismo de las rentas agrarias», Aportes. Revista de Historia Contemporánea, 89, 2015, pp. 5-39.

Seco Serrano, Carlos, «Los Episodios Nacionales como fuente histórica», Cuadernos Hispanoamericanos, 250-252, 1970-1971, pp. 256-284.

Sevillano Calero, Francisco y Emilio Soler Pascual (eds.), Diarios de viaje de Fernando VII (I823 y I827-I828), Alicante, Universidad de Alicante, 2013. 


\section{REALIDAD Y FICCIÓN EN EL EPISODIO GALDOSIANO}

Tudesq, Andre «L'élargissement de la noblesse en France dans la première moitié du XIXe siècle», en Les noblesses europénnes au XIXe siècle. Actes du colloque de Rome, Rome, École Française de Rome, 1988 Pp. $121-135$.

Valera, Eduardo, Cartas de Pérez Galdós a Mesonero Romanos, Madrid, Artes gráficas municipales, 1943.

Wasson, Ellis, Aristocracy and the Modern World, New York, Palgrave Macmillan, 2006.

Whiston, John, «"Ficción verosímil" and "realidad documentada" in the second series of Galdos's Episodios Nacionales», en Galdós's House of Fiction: Papers Given at the Birmingham Galdos Colloquium, ed. Anthony H. Clarke and Eamonn J. Rodgers, Llangrannog, Dolphin Book Co., I99I, PP. I-I3. 